\title{
Statistical Analysis of Tribological Performance of Functionally Graded Copper Composite Using DOE
}

\author{
N. Radhika* and M. Sam \\ Department of Mechanical Engineering, Amrita School of Engineering, Coimbatore, Amrita Vishwa Vidyapeetham, India - 641112 \\ *Phone: +91 9443566174
}

\begin{abstract}
Integration of functionally grading and centrifugal casting has led to a major breakthrough in the field of tribology applications across industries. Heavy-duty applications like bearings undergo considerable wear, especially at the inner zone in extreme sliding conditions. This research investigates the dry sliding performance of $\mathrm{Cu}-11 \mathrm{Ni}-4 \mathrm{Si} / 10 \mathrm{wt} . \% \mathrm{Al}_{2} \mathrm{O}_{3}$ graded composite statistically and experimentally using a pin-on-disc wear tester. Microstructural analysis revealed maximum gradient concentration of ceramics towards the inner radial wall of developed composite. The elongated alumina structures prevented the granular dislocations, which initiates cracks in composites. The wear analysis was conducted based on Taguchi's L27 orthogonal array and regression models, at tribo-parameters (load-15, 25, $35 \mathrm{~N}$, slide velocity-1.5, 2.5, $3.5 \mathrm{~m} / \mathrm{s}$ and slide distance-750, 1500, $1250 \mathrm{~m}$ ). Hierarchical analysis on the influence of tribology factors using delta value ranking technique identified load as the most influential parameter on the rate of wear, followed by sliding velocity and sliding distance. This was statistically confirmed using the percentage of contribution of each parameter identified during the analysis of variance. Trend analysis of influential factors against wear response was studied using analysis of variance. The influence of process conditions and their interactions on the wear are also detailed. This had a major influence on the improvement of wear resistance. Wear raised with a proportional rise in load and distance. The worn surface analysis identified that the formation of mechanically mixed layers at intermediate velocity has significantly limited the wear rate. This developed composite is suggestable for diverse automobile components of various tribology applications.
\end{abstract}

ARTICLE HISTORY

Received: $5^{\text {th }}$ March 2021

Revised: gth $^{\text {th }}$ Aug 2021

Accepted: $3^{\text {rd }}$ Sept 2021

\section{KEYWORDS}

Materials;

Casting;

Copper;

Microscopy;

Tribology

\section{INTRODUCTION}

Composites reinforced with ceramics have been studied for many years at the macro scale for improving their mechanical applications. At the same time, its research on tribological applications is still exhibiting a huge gap between its experimental impact and industrial applicability. In order to achieve the uniqueness of combining superior properties of matrix and reinforcements, metal matrix composites (MMCs) were preferred by Purushothaman [1] during his wearcorrosion study. According to Chen et al. [2], the rising requirements for light-weightiness, stiffness, and strength has led to the research and development of novel MMCs, eradicating the conventional base material. The commonly used matrix materials in MMCs are $\mathrm{Al}, \mathrm{Cu}, \mathrm{Zn}$, and $\mathrm{Mg}$; copper and aluminium are widely preferred. Aluminium is less dense; hence it is unsuitable for many mechanical component applications, as studied by Radhika [3] and Sam [4]. Copper, in its high purity state has become an integral part of the household and industrial wiring, ignition spark plugs and HVAC condenser tubes. According to Radhika et al., supreme electro-thermal conductivity with low thermal expansion, ductile nature and high melting point were the key features of copper that widened its popularity [5]. As per the findings of Efe et al. [6], $\mathrm{Cu}$ with 1-5 wt.\% SiC displayed 5\% improved hardness and bonding strength due to the good mixing of reinforcement particles with the copper matrix. Factors like particle interface moduli, volume percentile, shape and distribution directly impacts the load transfer over particle, as observed by Rajkovic [7].

Certain industrial and automotive applications require an optimum negotiation between toughness and hardness. Those were met by the spatial gradation facilitating superior toughness and hardness balance. For this, an advanced class of material known as FGM was used by Sobczak [8]. Desirable properties like anti-wear and thermal conductivity can also be formulated selectively for better functional applications, as reported by Rajan [9]. It was achieved practically by Malekzadeh [10] through confining a higher presence of denser components towards the required wall zone. Many manufacturing techniques like powder metallurgy, deposition techniques, casting and spraying were preferred to fabricate FGM. Paul [11] suggests centrifugal casting as the most preferred and reliable over other fabrication techniques due to its low cast irregularities, good physical strength and advantageous metallurgical structure. $\mathrm{Cu}-5 \mathrm{wt} . \% \mathrm{WC}$ with indium doping was subjected to non-lubricated slide tribology investigation by Hong et al. [12], which revealed $38 \%$ improvement in anti-wear when tested on a tribo-tester under normal load (of $10 \mathrm{~N}$ ). Tribo-mechanical analysis of functional grade $\mathrm{Cu}-15 \mathrm{NbC}$ composite attained improvements of $40 \%$ and $50 \%$ respectively than its alloy when studied by Shiri et al. [13]. Gautam et al. [14], in a comparative study, concludes that $\mathrm{Cr}$ addition improved the matrix strength 
improving mechanical performance, whereas $\mathrm{SiC}$ improved anti-wearing of the composite when mixed with pure copper. Tribo-analysis of $\mathrm{Cu}+\mathrm{MoS}_{2}$ using Taguchi technique, Kumar [15] determined sliding distance as the most influential parameter under non-lubricated conditions. This was unique as the majority of the researchers concluded load as the most influential parameter. This work attempts to determine the unexplored non-lubricated slid characteristics of $\mathrm{Cu}-\mathrm{Ni}-\mathrm{Si}$ alloy when mixed with $\mathrm{Al}_{2} \mathrm{O}_{3}(10 \mathrm{wt} . \%)$ fabricated through functionally grading. The wear of the composite was statistically evaluated and analysed using the design of experiments (DOE).

\section{METHODOLOGY}

\section{Materials}

The copper of $8.94 \mathrm{~g} / \mathrm{cm}^{3}$ density is best preferred as matrix materials for ceramic graded composites due to its exceptional capability to limit particle pull-outs and induce supreme mechanical performance. Pure copper does not have proper wettability with reinforcement particles; hence nickel and silicon were added as alloying elements to ensure proper wettability with the particles. Silicon provides better wettability and machining properties. In order to increase the antiwearing, the matrix was mixed with $\mathrm{Al}_{2} \mathrm{O}_{3}$ (of $10 \mu \mathrm{m}$ average size). Copper was mixed of 11 wt. $\%$ of nickel, 4 wt. $\%$ of silicon, forming the matrix alloy composition. This was further reinforced with $\mathrm{Al}_{2} \mathrm{O}_{3}(10 \mathrm{wt} . \%)$, using a stir casting route to form a graded composite. Casting the composites through liquid metallurgy provides excellent adhesive bonding at the matrix-ceramic interface. According to Nai et al. [16], the overall ceramic presence is limited within the range of 5-10 wt. $\%$ for composites because $<5 \mathrm{wt} . \%$ results in a lack of homogeneity and $>10 \mathrm{wt} . \%$ causes clustering effect. The alumina particles observed (in Figure 1) through SEM revealed an elongated shape with blunt corners. This facilitates better void occupancy and in turn, strengthens the composite.

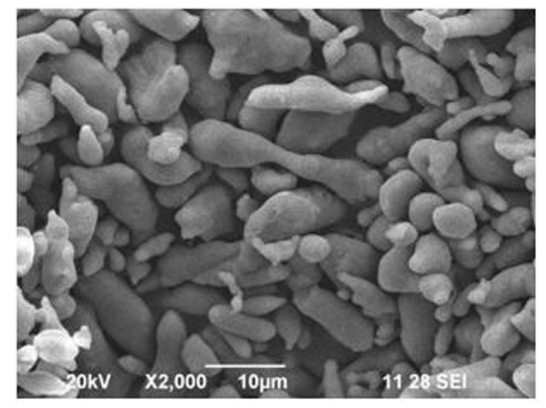

Figure 1. SEM of the particle reinforcements.

\section{Composite Synthesis and Analysis of Microstructure}

This graded copper functional composite was stir cast as it is one among the liquid state synthesis methods, where ceramic strengthens the molten matrix. Copper ( $85 \mathrm{wt} . \%$ ) was melted in a furnace of maximum temperature capacity of $1500{ }^{\circ} \mathrm{C}$. To fabricate the copper alloy, compositional elements like nickel and silicon were mixed with copper to melt under an inert atmosphere. The molten alloy was stirred for 5 minutes at $150 \mathrm{rpm}$, to which the pre-heated $\left(200{ }^{\circ} \mathrm{C}\right) \mathrm{Al}_{2} \mathrm{O}_{3}$ $(10 \mathrm{wt} . \%)$ particles were added. Later, the melt $\left(1060^{\circ} \mathrm{C}\right)$ was poured into a rotating (at $\left.900 \mathrm{rpm}\right)$ centrifuge mould (preheated at $350{ }^{\circ} \mathrm{C}$ ); to solidify as a hollow cast of $\Phi_{\text {out }} 100 \mathrm{~mm} \times \Phi_{\text {in }} 85 \mathrm{~mm} \times 100 \mathrm{~mm}$, as shown in Figure 2(a). The microstructural analysis (Figure $2 \mathrm{~b}$ ) carried out at inner layer depict ceramic richness and non-clustered distribution within the copper matrix. Combining horizontal centrifugal technique with the ceramic selection of lower density (compared to matrix) have facilitated graded distribution along the radial wall and maximum concentration at the inner wall zone.

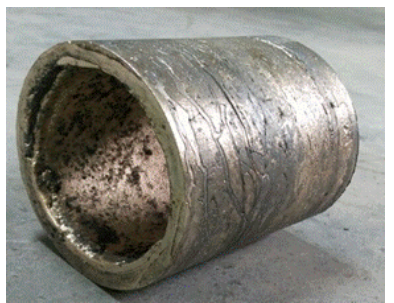

(a)

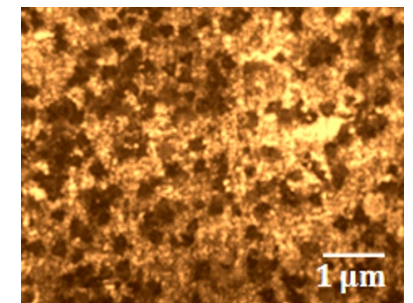

(b)

Figure 2. (a) Centrifuge cast composite sample, and (b) Ceramic distribution at the inner wall layer.

\section{Adhesive Tribology}

Non-lubricated tribology tests were performed based on ASTM G 99, using sample pins made from the inner wall tested over disc tribo-tester at an unchanged track diameter of $90 \mathrm{~mm}$. The varied influencing factors used are loads of 15-35 N, slide distance of 750-2250 m and slide velocities of 1.5-3.5 m/s. Kaliyannan et al. [17] have reported that the impact of cyclic stress over the material interface exhibits adhesive phenomenon on tribology. The cyclic rate of specific 
wear was compute using Archard's equation mentioned by Czichos et al. [18] in the Springer measurement handbook, as shown in Eq. (1).

$$
W=\frac{M}{\rho F D}
$$

where $W$ is rate of wear in $\mathrm{mm}^{3} / \mathrm{m}, M$ is mass reduction in grams, $F$ is normal load in $\mathrm{N}, \rho$ is density in $\mathrm{g} / \mathrm{mm}^{3}$ and $D$ is slide distance in $\mathrm{m}$.

\section{Design of Experiments}

Design of experiments (DOE) aims to minimise the number of experimental trials without compromising quality. This approach significantly reduces the overall experimental cost. Each influential parameter is varied at 3-levels using Minitab to structure the plan of experiments effectively. The structure of Table 3 is based on the $\mathrm{L}_{27}$ orthogonal array where three influential factors - applied load, sliding distance and sliding velocity is varied at three levels to attain 27 parametric combinations for trials. Each test trial was repeated thrice in order to confirm its repeatability. The mean of these repeated trial values was plotted, and their standard deviation is represented with error bars.

\section{RESULTS AND DISCUSSION}

\section{Tribological Behaviour of Composite}

As the composite is developed for bearing application, it undergoes rotational wear than reciprocating wear. Hence pin-on-disc tribo-tester was preferred rather than the pin-on-plate reciprocating wear tester. The tribological behaviour of the composite specimen and the worn surface analysis using SEM and micrographs are explained below.

Microstructural analysis revealed a higher presence of alumina towards the inner radial wall of the developed composite sample. The tribology test at non-lubricated conditions was conducted for this zone, where their corresponding wear is tabulated in Table 1. The DOE classifies information with the least number of trials. The rate of wear was a response function of tribo-factors like load, slide distance, and velocity.

Table 1. Experimental values and their signal-to-noise ratios.

\begin{tabular}{|c|c|c|c|c|c|}
\hline S. No. & Load, L (N) & Slide distance, SD (m) & Slide velocity, SV $(\mathrm{m} / \mathrm{s})$ & Wear, W $\left(\mathrm{mm}^{3} / \mathrm{m}\right)$ & $\mathrm{S} / \mathrm{N}$ ratio $(\mathrm{dB})$ \\
\hline 1 & 15 & 750 & 1.50 & 0.0002020 & 73.8930 \\
\hline 2 & 15 & 750 & 2.50 & 0.0000380 & 88.4043 \\
\hline 3 & 15 & 750 & 3.50 & 0.0002170 & 73.2708 \\
\hline 4 & 15 & 1500 & 1.50 & 0.0001480 & 76.5948 \\
\hline 5 & 15 & 1500 & 2.50 & 0.0000560 & 85.0362 \\
\hline 6 & 15 & 1500 & 3.50 & 0.0001750 & 75.1392 \\
\hline 7 & 15 & 2250 & 1.50 & 0.0003570 & 68.9466 \\
\hline 8 & 15 & 2250 & 2.50 & 0.0000310 & 90.1728 \\
\hline 9 & 15 & 2250 & 3.50 & 0.0003710 & 68.6125 \\
\hline 10 & 25 & 750 & 1.50 & 0.0002280 & 72.8413 \\
\hline 11 & 25 & 750 & 2.50 & 0.0000460 & 86.7448 \\
\hline 12 & 25 & 750 & 3.50 & 0.0003110 & 70.1448 \\
\hline 13 & 25 & 1500 & 1.50 & 0.0002580 & 71.7676 \\
\hline 14 & 25 & 1500 & 2.50 & 0.0001960 & 74.1549 \\
\hline 15 & 25 & 1500 & 3.50 & 0.0003980 & 68.0023 \\
\hline 16 & 25 & 2250 & 1.50 & 0.0002760 & 71.1818 \\
\hline 17 & 25 & 2250 & 2.50 & 0.0001951 & 74.1949 \\
\hline 18 & 25 & 2250 & 3.50 & 0.0003640 & 68.7780 \\
\hline 19 & 35 & 750 & 1.50 & 0.0003650 & 68.7541 \\
\hline 20 & 35 & 750 & 2.50 & 0.0001630 & 75.7562 \\
\hline 21 & 35 & 750 & 3.50 & 0.0004700 & 66.5580 \\
\hline 22 & 35 & 1500 & 1.50 & 0.0012410 & 58.1246 \\
\hline 23 & 35 & 1500 & 2.50 & 0.0002750 & 71.2133 \\
\hline 24 & 35 & 1500 & 3.50 & 0.0013810 & 57.1961 \\
\hline 25 & 35 & 2250 & 1.50 & 0.0013950 & 57.1085 \\
\hline 26 & 35 & 2250 & 2.50 & 0.0002561 & 71.8352 \\
\hline 27 & 35 & 2250 & 3.50 & 0.0014990 & 56.4840 \\
\hline
\end{tabular}

Hierarchy on the influence of each tribology parameter (load, slide velocity, slide distance) is displayed in Table 2. This ranking of hierarchy is determined from the delta value. Load impacted as the major adhesive wear factor. Slide velocity and sliding distance are observed as second and third-ranked factors considering their influence on wear rate. $\mathrm{S} / \mathrm{N}$ ratio plot (in Figure 3) determines the optimum parametric conditions (at $15 \mathrm{~N}, 750 \mathrm{~m}, 2.5 \mathrm{~m} / \mathrm{s}$ ) for minimum wear. 
Figure 4 shows the main effect plot on data means. The trend of wear rate against each influential factor is graphically analysed.

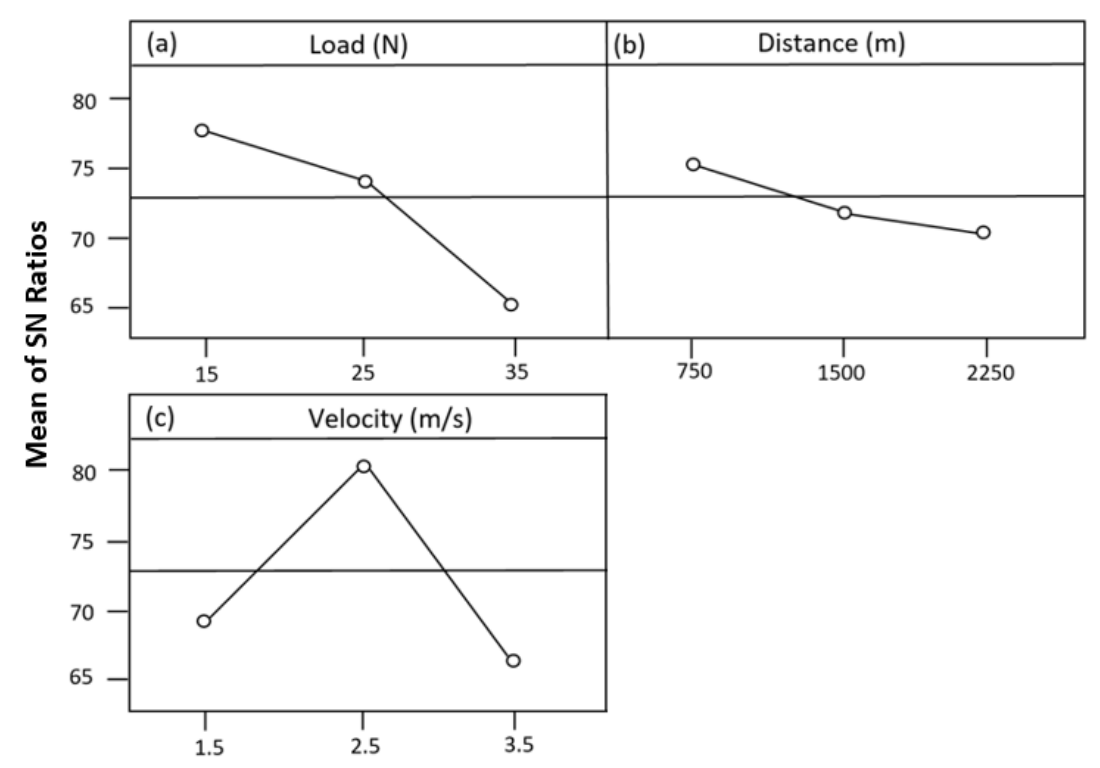

Figure 3. S-N ratio plot.

Table 2. Hierarchy of influence of tribology factors.

\begin{tabular}{lccc}
\hline Level & Load $(\mathrm{N})$ & Sliding distance $(\mathrm{m})$ & Sliding velocity $(\mathrm{m} / \mathrm{s})$ \\
\hline 1 & 78.8 & 76.2 & 69.8 \\
2 & 72.1 & 71.8 & 78.7 \\
3 & 64.8 & 69.7 & 67.1 \\
Delta & 13.0 & 5.5 & 12.6 \\
Rank & 1 & 3 & 2 \\
\hline
\end{tabular}

\section{Effect of Load on Tribology}

Wear increased variably with the rise in load parameter, as shown in Figure 4(a). A slight rise in wear was seen (from $15 \mathrm{~N}$ to $25 \mathrm{~N}$ ) initially, whereas a substantial rise was seen from $25 \mathrm{~N}$ to $35 \mathrm{~N}$. At minimum load (of $15 \mathrm{~N}$ ), features of meagre wear were observed, which later varied directly at a slower rate with applied load up to $25 \mathrm{~N}$. Increased period of sliding, raised tribology factors (temperature and pressure) at a raised load of $35 \mathrm{~N}$. At the same condition, plastic behaviour observed to dominate over the sliding specimen causing adhesion of test sample material over the disc. Sam et al. [19 ] made a similar interpretation during their tribology study where ploughing and delamination caused extra material removal, transforming wear normal to severe. The elongated alumina structures prevent the granular dislocations, which initiates crack in composites under cyclic loads. Consecutive dislocations induced back stress, which restricts further dislocation. The reinforcements bear load at their sites, apparently transmitting load towards the matrix, thereby significantly reducing wear.

\section{Effect of Slide Distance on Tribology}

The wear rate proportionally increased with the rise in slide distance, as in Figure 4(b). During a shorter distance (of $750 \mathrm{~m}$ ), hard particle presence promoted dispersion hardening over the test specimen surface. It enables effective bonding at the matrix-reinforcement interface states in Moganapriya et al. [20] during their wear study on multi-layered composites. A slight decrement in the rate of rising of wear response was seen from $1500 \mathrm{~m}$ to $2250 \mathrm{~m}$ when compared to that observed in the range of $750 \mathrm{~m}$ to $1500 \mathrm{~m}$. This was because, at a moderate slide distance (of $1500 \mathrm{~m}$ ), the cyclic stress induction resulted in normal wear. This fatigue stress induction with prolonged distance (of $2250 \mathrm{~m}$ ); declined the matrix-particle interactive strength. This also resulted in particle-matrix bond wreckage, causing a further rise in wear.

\section{Effect of Slide Velocity on Tribology}

The influence of slide velocity over wear showed a valley curve at critical velocity (of $2.5 \mathrm{~m} / \mathrm{s}$ ), as in Figure 4(c). The subsequent layering of oxides, termed as a mechanically mixed layer (MML), facilitated this at the intermediate velocity (of $2.5 \mathrm{~m} / \mathrm{s}$ ). Debris produced out of micro-cuts underwent oxidisation to accumulate a compact layer. This layer collects interfacial contributions from both sliding surfaces. While at least velocity $(1.5 \mathrm{~m} / \mathrm{s})$, the frictional heat at the interface promoted oxidation. When further, the velocity raised (from $1.5 \mathrm{~m} / \mathrm{s}$ to $2.5 \mathrm{~m} / \mathrm{s}$ ), the tribolayer that formed acts as a hindrance to wear or act as an interfacial lubricant, decreasing wear. The same phenomenon was quoted by Zhang et al. [21] during the dry sliding tribo-study on SiC-based composites. At peak velocity $(3.5 \mathrm{~m} / \mathrm{s})$, this accumulation gets scrapped to expose the adjacent tier particles, thereby spiking the wear due to delamination. 


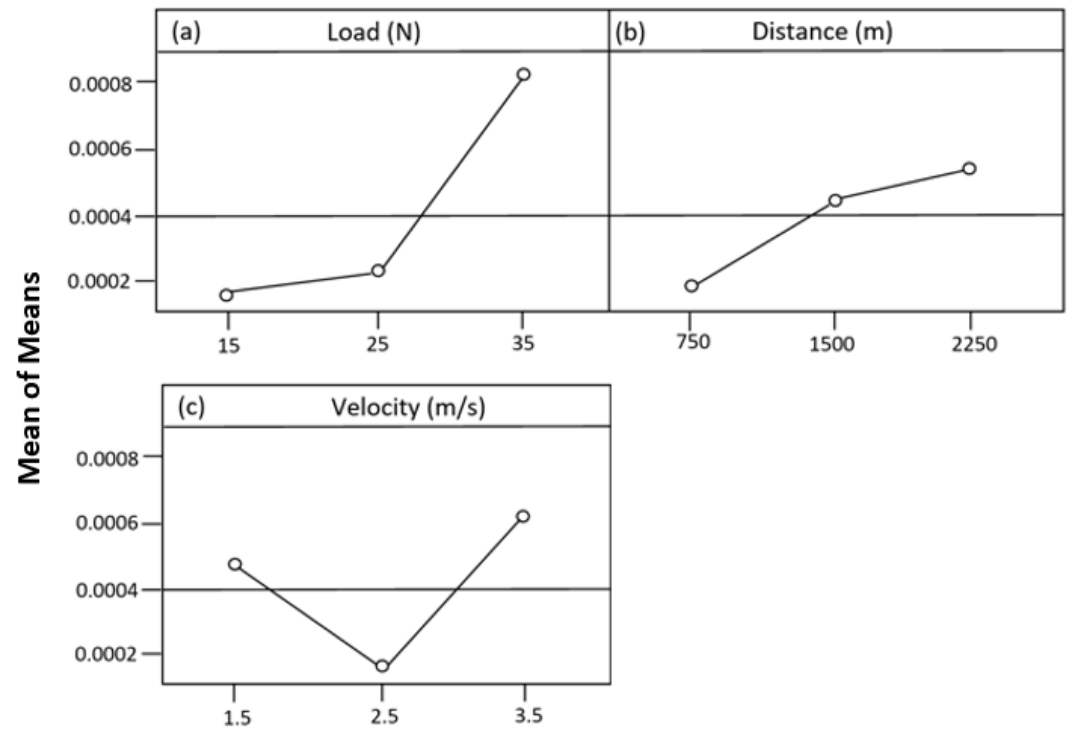

Figure 4. Main effect plot on data means.

\section{Analysis of Variance}

Table 3 shows the result of ANOVA analysis for wear rate with a confidence interval of $95 \%$ and significance level of $5 \%$. The total variation of experimental observations attributed to each influential factor, also considering their interactions, is represented as per cent contribution $(\mathrm{P} \%)$. This identifies the most influential factor causing minimal variation. The parameters that affect the wear rate are considered to possess a P-value less than 0.05 . From the results, it is concluded that load has the highest influence (at 41.67\%) on wear rate, followed by sliding velocity (at 20.83\%) and sliding distance (at 8.33\%). Interactions of load and sliding distance (at 10.41\%) along with interactions of load and sliding velocity (at $12.50 \%$ ) also showed significant influence over wear rate.

Table 3. ANOVA for wear rate.

\begin{tabular}{lccccccc}
\hline Source & $\begin{array}{c}\text { Degrees } \\
\text { of } \\
\text { freedom }\end{array}$ & $\begin{array}{c}\text { Sequential } \\
\text { sum of } \\
\text { squares } \\
\left(\times 10^{-6}\right)\end{array}$ & $\begin{array}{c}\text { Adjacent } \\
\text { sum of } \\
\text { squares } \\
\left(\times 10^{-6}\right)\end{array}$ & $\begin{array}{c}\text { Adjacent } \\
\text { mean } \\
\text { squares } \\
\left(\times 10^{-6}\right)\end{array}$ & F & $\begin{array}{c}\text { Probability } \\
\text { values } \\
\left(\times 10^{-2}\right)\end{array}$ & $\begin{array}{c}\text { Percentage of } \\
\text { contribution } \\
(\mathrm{P} \%)\end{array}$ \\
\hline Load (N) & 2 & 0.2 & 0.2 & 1.0 & 31.98 & 0.0 & 41.67 \\
$\begin{array}{l}\text { Distance (m) } \\
\text { Velocity (m) }\end{array}$ & 2 & 0.4 & 0.4 & 0.2 & 7.28 & 1.6 & 08.33 \\
Load (N)* & 2 & 1.0 & 1.0 & 0.5 & 15.88 & 0.2 & 20.83 \\
distance (m) & 4 & 0.5 & 0.5 & 0.1 & 4.22 & 4.0 & 10.41 \\
Load (N)* & 4 & 0.1 & 0.1 & 0.0 & 0.93 & 4.91 & 12.50 \\
velocity (m/s) & & & & & & & \\
$\begin{array}{l}\text { Distance (m)* } \\
\text { velocity (m/s) }\end{array}$ & 4 & 0.6 & 0.6 & 0.1 & 4.61 & 3.2 & 02.08 \\
Error & 8 & 0.2 & 0.2 & 0.0 & & & 04.17 \\
Total & 26 & 0.5 & & & & & \\
\hline
\end{tabular}

\section{Regression Analysis and Experiment Validation}

The relationship between variable factors is estimated using a statistical process called regression analysis. It follows a mathematical approach of correlating the influential parameters (load, slide distance and slide velocity) for the effective computation of wear and analysing its variation with the experimental values. The regression equation is in Eq. (2).

$$
\mathrm{W}=-0.00017+0.000007 \mathrm{~L}+0.000002 \mathrm{D}-0.000022 \mathrm{~V}-0.00002 \mathrm{~L} \times \mathrm{V}
$$

where L, D and V stands for applied load $(\mathrm{N})$, slide distance $(\mathrm{m})$ and slide velocity $(\mathrm{m} / \mathrm{s})$, respectively. The regressive comparison validating experimental wear values in Table 4 limits the error value below $3 \%$.

Table 4. Validation of experimental wear values.

\begin{tabular}{lcccccc}
\hline S. No. & $\mathrm{L}(\mathrm{N})$ & $\mathrm{S} \mathrm{V}(\mathrm{m} / \mathrm{s})$ & $\mathrm{S} \mathrm{D}(\mathrm{m})$ & $\begin{array}{c}\text { Practical wear } \\
\text { rate }\left(\mathrm{mm}^{3} / \mathrm{m}\right)\end{array}$ & $\begin{array}{c}\text { Mathematical regression wear } \\
\text { rate }\left(\times 10^{-4} \mathrm{~mm}^{3} / \mathrm{m}^{2}\right)\end{array}$ & $\begin{array}{c}\text { Error } \\
(\%)\end{array}$ \\
\hline 1 & 18 & 1.7 & 755 & 8.07 & 8.17 & 1.19 \\
2 & 16 & 1.8 & 800 & 9.00 & 9.26 & 2.97 \\
3 & 17 & 1.6 & 720 & 8.07 & 8.10 & 0.34 \\
\hline
\end{tabular}




\section{Scanning Electron Microscopy Analysis}

Elaborative and intensive interpretations of the wear mechanisms involved during dry sliding were conducted through SEM analysis, as shown in Figure 5(a) to 5(f). This preferred technique was an effective tool to reveal transition mechanisms in detail. Wear was found to be least at a minimum load of $15 \mathrm{~N}$ in Figure 5(a), resulting in mild wear. The wear of the developed composite was directly limited by the alumina particles. Apparent cracks were induced at the matrix at a high load (of $35 \mathrm{~N}$ ). Adhesion phenomenon was observed in Figure 5(b), causing excessive material removal due to ploughing and delamination. A similar transition (mild to severe) mechanism was reported by Cao et al. [22] at higher loads during dry sliding of copper hybrid ( $\mathrm{Gr}$ and $\mathrm{TiC}$ ) composite.

Slide velocity (of $1.5 \mathrm{~m} / \mathrm{s}$ and $2.5 \mathrm{~m} / \mathrm{s}$ ) varied at fixed slide distance (of $1500 \mathrm{~m}$ ), and load (of $25 \mathrm{~N}$ ) is shown in Figure $5(\mathrm{c})$ and 5(d), respectively. At a minimum slide velocity of $1.5 \mathrm{~m} / \mathrm{s}$ in Figure 5(c), high wear features like micro-cuts were seen along their slide direction. Grooves and scraps that occurred due to the greater interfacial contact are results of matrix-particle bond wreckage under prolonged contact conditions. Due to these, abrasive wear was observed to be dominant at minimum slide velocity (of $1.5 \mathrm{~m} / \mathrm{s}$ ), which resulted in high wear. The composite sample worn at an intermediate slide velocity of $2.5 \mathrm{~m} / \mathrm{s}$ in Figure 5(d) revealed minimal scratches with wider grooves, pointing towards minimum wear. This was also due to the formation MML tribolayer, as observed similarly by Sam et al. [23] during the dry condition tribo-study on aluminium FGM. This layer got scrapped off with a subsequent rise in sliding velocity.

Varied slide distances (of 750 and $2250 \mathrm{~m}$ ) at fixed load (of $15 \mathrm{~N}$ ) and slide velocity (of $1.5 \mathrm{~m} / \mathrm{s}$ ) influenced worn surface as shown in Figure 5(e) and 5(f), respectively. At a short distance $(750 \mathrm{~m})$, minor scratches were expressed in Figure 5(e) along the slid direction. The wear of the composite was limited due to the high presence of elongated hard ceramics over the worn sample. An increase in severity of wear is seen in Figure 5(f) with prolonged slide distance (up to $2250 \mathrm{~m}$ ). Accumulation of wear debris induced third body abrasion where suspended particles tend to scrap the matrix during sliding action. As the tribo-particles resist this penetration, gouging and particle pull-outs were observed, those resulting in severe wear. Broad ploughing features, as reported by Kanagarajan [24] were caused by the grinding action of ceramics during sliding.

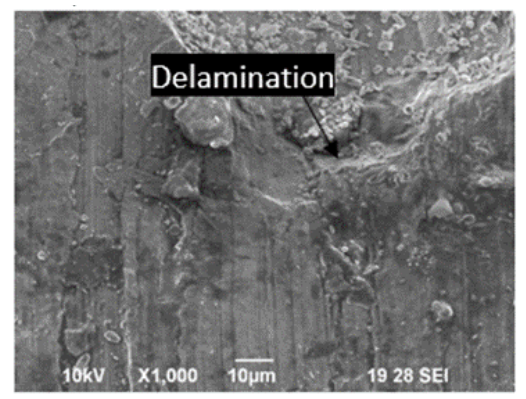

(a)

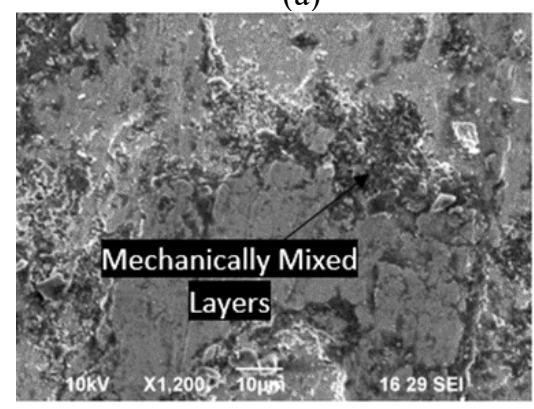

(d)

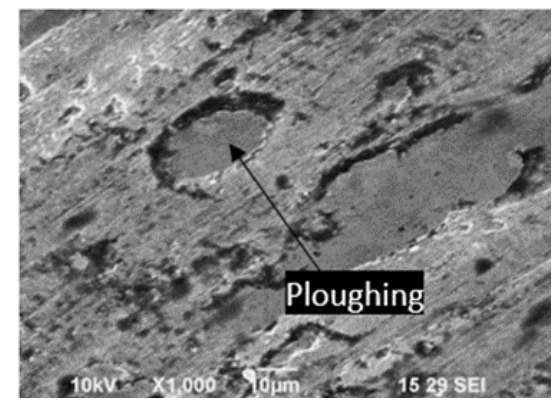

(b)

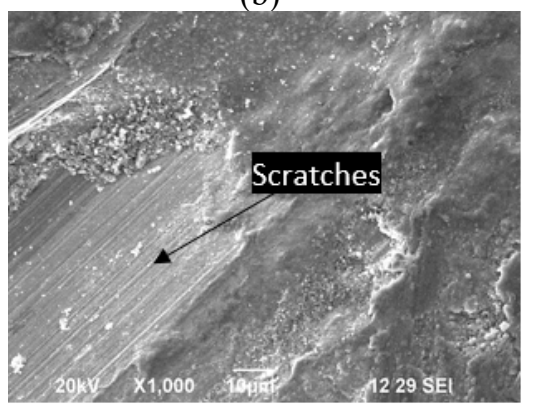

(e)

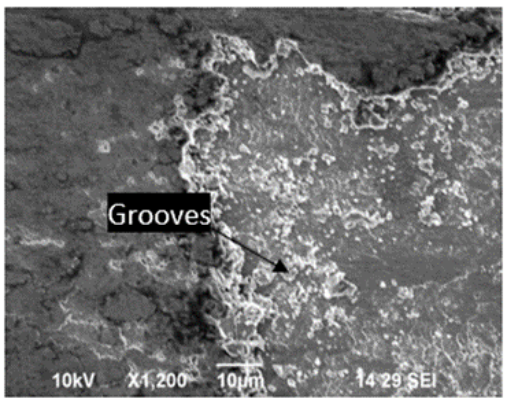

(c)

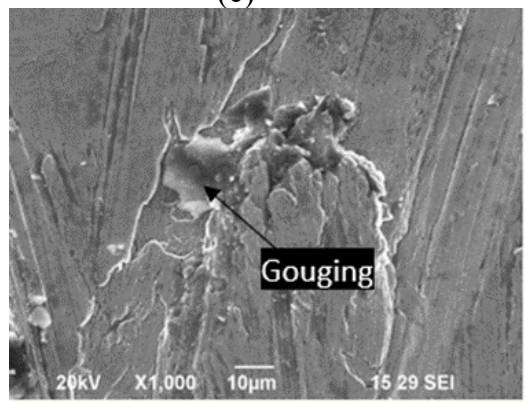

(f)

Figure 5. SEM of composite samples worn at different conditions of (a) $\mathrm{L}=15 \mathrm{~N}, \mathrm{D}=2250 \mathrm{~m}$ and $\mathrm{V}=2.5 \mathrm{~m} / \mathrm{s}$ (b) $\mathrm{L}=35 \mathrm{~N}, \mathrm{D}=1500 \mathrm{~m}$ and $\mathrm{V}=2.5 \mathrm{~m} / \mathrm{s}$, (c) $\mathrm{L}=25 \mathrm{~N}, \mathrm{D}=1500 \mathrm{~m}$ and $\mathrm{V}=1.5 \mathrm{~m} / \mathrm{s}$, (d) $\mathrm{L}=25 \mathrm{~N}, \mathrm{D}=1500 \mathrm{~m}$ and $\mathrm{V}=2.5 \mathrm{~m} / \mathrm{s}$, (e) $\mathrm{L}=15 \mathrm{~N}, \mathrm{D}=750 \mathrm{~m}$ and $\mathrm{V}=1.5 \mathrm{~m} / \mathrm{s}$, and (f) $\mathrm{L}=15 \mathrm{~N}, \mathrm{D}=2250 \mathrm{~m}$ and $\mathrm{V}=1.5 \mathrm{~m} / \mathrm{s}$.

Oxidisation of the worn sample surface was evaluated by EDAX analysis in Figure 6, which confirmed the presence of oxides that formed the tribolayer on the pin surface, thus reducing the amount of wear formed. The composite sample worn under optimum condition (of $\mathrm{L}=15 \mathrm{~N}, \mathrm{D}=750 \mathrm{~m}$ and $\mathrm{V}=2.5 \mathrm{~m} / \mathrm{s}$ ) produced few wear tracks, scratches and grooves, as shown in Figure 7. These features are categorised as mild tribology effects. 


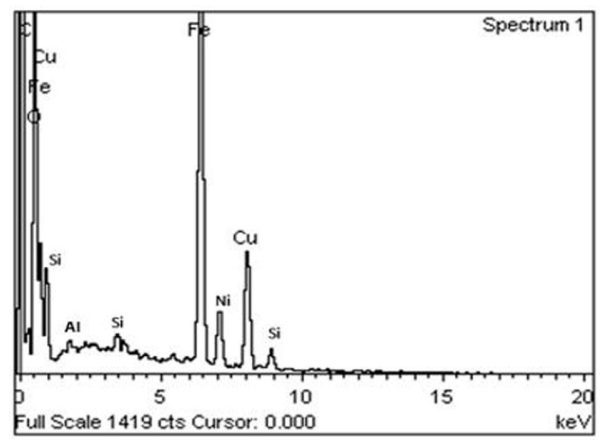

Figure 6. EDX result for the worn composite sample.

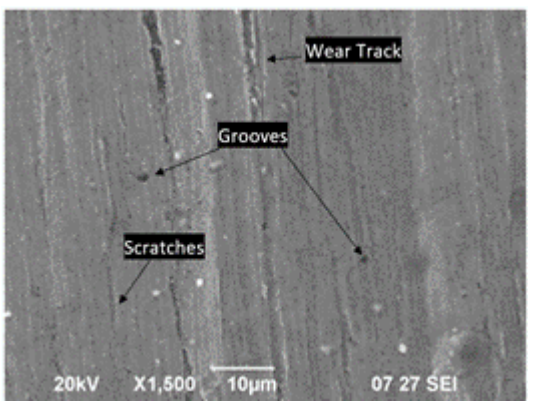

Figure 7. SEM of optimum worn sample.

\section{CONCLUSION}

Functional graded $\mathrm{Cu} 11 \mathrm{Ni} 4 \mathrm{Si}+10 \mathrm{wt} . \% \mathrm{Al}_{2} \mathrm{O}_{3}$ composite was centrifuge cast. Tribology test conducted at nonlubricated environment revealed direct relation of wear with load and slide distance, whereas with slide velocity, it revealed a V-trend. The load was identified as the most influential factor (41.67\%) over wear. The signal-noise proportion and analysis of variance predicted the optimum tribo-conditions at load of $15 \mathrm{~N}$, velocity of $2.5 \mathrm{~m} / \mathrm{s}$ and distance of 750 $\mathrm{m}$ for minimum wear. SEM analysis on the worn sample surfaces emphasised transition (like mild to normal and normal to severe) of wear along with the rise in load. Features revealing the wear mechanisms at the intermediate velocities were observed, and the formation of MML was later confirmed using EDAX. Research on tribology behaviour of this developed composite suggests it for different automobile components like heavy-duty bearings.

\section{ACKNOWLEDGEMENT}

The authors are truly obliged to Defence Research and Development Organization (DRDO) for the financial support.

\section{REFERENCES}

[1] L. Purushothaman and P..Balakrishnan, "Wear and corrosion behavior of coconut shell ash (CSA) reinforced Al6061 metal matrix composites," Mater. Test., vol. 62, no. 1, pp. 77-84, 2020, doi: 10.3139/120.111456.

[2] B. Chen et al., "Tribological properties of copper-based composites with copper-coated $\mathrm{NbSe}_{2}$ and CNT," Mater. Des., vol. 75, pp. 24-31, 2015, doi: 10.1016/j.matdes.2015.03.012.

[3] N. Radhika and R. Raghu, "Dry sliding wear behaviour of aluminium Al-Si12Cu/TiB 2 metal matrix composite using response surface methodology," Tribol. Lett., vol. 59, no. 1, pp. 1-9, 2015, doi: 10.1007/s11249-015-0516-3.

[4] M. Sam and N. Radhika, "Comparative study on reciprocal tribology performance of mono-hybrid ceramic reinforced Al-9Si3Cu graded composites," Silicon, vol. 1, pp. 1-7, 2021, doi.org/10.1007/s12633-020-00623-x.

[5] N. Radhika, J. Sasikumar, and J. Arulmozhivarman, "Tribo-mechanical behaviour of Ti-based particulate reinforced As-cast and heat treated A359 composites," Silicon, vol. 1, pp. 1-4, 2020, doi.org/10.1007/s12633-019-00370-8.

[6] G.C. Efe et al., "An investigation of the effect of $\mathrm{SiC}$ particle size on $\mathrm{Cu}-\mathrm{SiC}$ composites," Compos. B. Eng., vol. 43, no. 4, p. 1813-1822, 2012, doi: 10.1016/j.compositesb.2012.01.006.

[7] V. Rajkovic, D. Bozic, J. Stasic, H. Wang, and MT. Jovanovic, "Processing, characterization and properties of copper-based composites strengthened by low amount of alumina particles," Powder Technol., vol. 268, pp. 392-400, 2014, doi: 10.1016/j.powtec.2014.08.051.

[8] J.J. Sobczak and L. Drenchev, "Metallic functionally graded materials: a specific class of advanced composites," J Mater Sci Technol., vol. 29, no. 4, pp. 297-316, 2013, doi: 10.1016/j.jmst.2013.02.006.

[9] T.P. Rajan and B.C. Pai, "Processing of functionally graded aluminium matrix composites by centrifugal casting technique," Mater. Sci. Forum, vol. 690, pp. 157-161, 2011, doi: 10.4028/www.scientific.net/MSF.690.157.

[10] P. Malekzadeh, "Three-dimensional free vibration analysis of thick laminated annular sector plates using a hybrid method," Compos. Struct., vol. 90, no. 4, pp. 428-437, 2009, doi: 10.1016/j.compstruct.2008.08.007. 
[11] C. Paul and R. Sellamuthu, "Effect of nickel content on hardness and wear behaviour of surface modified functionally graded Cu-Sn bronze alloy," Int. J. Mater. Eng. Innov., vol. 7, no. 1, pp. 43-55, 2016, doi: 10.1504/IJMATEI.2016.077316.

[12] E. Hong et al., "Tribological properties of copper alloy-based composites reinforced with tungsten carbide particles," Wear, vol. 270, no. 9-10, pp. 591-597, 2011, doi: 10.1016/j.wear.2011.01.015.

[13] S.G. Shiri et al., "Preparation of in-situ $\mathrm{Cu} / \mathrm{NbC}$ nanocomposite and its functionally graded behavior for electrical contact applications," Trans. Nonferrous Met. Soc. China, vol. 25, no. 3, pp. 863-872, 2015, doi: 10.1016/S1003-6326(15)63675-5.

[14] R.K. Gautam et al., "Tribological behavior of $\mathrm{Cu}-\mathrm{Cr}-\mathrm{SiCp}$ in situ composite," Wear, vol. 265, no. 5-6, p. 902-912, 2008, doi: 10.1016/j.wear.2008.01.023.

[15] P.S. Kumar and K. Manisekar, "Prediction of effect of $\mathrm{MoS}_{2}$ content on wear behavior of sintered Cu-Sn composite using Taguchi analysis and artificial neural network," Indian J. Eng. Mater. Sci., vol. 21, no. 6, pp. 657-671, 2014, http://hdl.handle.net/123456789/30525.

[16] S.M.L. Nai, M. Gupta, and C.Y.H. Lim, "Synthesis and wear characterization of Al based, free standing functionally graded materials: effects of different matrix compositions," Compos Sci Technol., vol. 63, p. 1895-1909, 2003, doi: 10.1016/S02663538(03)00158-1.

[17] G.V. Kaliyannan et al., "Mechanical and tribological behavior of SiC and fly ash reinforced Al 7075 composites compared to SAE 65 bronze," Mater. Test., vol. 60, no. 12, pp. 1225-1231, 2018, doi: 10.3139/120.111272.

[18] H. Czichos and T. Saito, Springer Handbook of Materials Measurement Methods, Smith L, editor. Berlin: Springer, 2006 May, doi: 10.1007/978-3-540-30300-8.

[19] M. Sam and N. Radhika, "Mechanical and tribological analysis of functionally graded aluminium hybrid composite using RSM approach," Mater. Res. Express, vol. 6, 096595, 2019, doi: 10.1088/2053-1591/ab3168.

[20] C. Moganapriya et al., "Tribomechanical behavior of TiCN/TiAlN/WC-C multilayer film on cutting tool inserts for machining," Mater. Test., vol. 59, no. 7-8, p. 703-707, 2017, doi: .10.3139/120.111060

[21] L. Zhang et al., "Dry sliding wear properties of high volume fraction $\mathrm{SiCp} / \mathrm{Cu}$ composites produced by pressureless infiltration," Wear, vol. 265, no. 11-12, p. 1848-1856, 2008, doi: 10.1016/j.wear.2008.04.029.

[22] H. Cao et al., "Tribological behavior of Cu matrix composites containing graphite and tungsten disulfide," Tribol. Trans., vol. 57, no. 6, pp. 1037-1043, 2014, doi: 10.1080/10402004.2014.931499.

[23] M. Sam and N. Radhika, "Influence of carbide ceramic reinforcements in improving tribological properties of A333 graded hybrid composites," Def. Technol., 2021, doi: 10.1016/j.dt.2021.06.005.

[24] P. Kanakarajan et al., "Acoustic emission testing of surface roughness and wear caused by grinding of ceramic materials," Mater. Test., vol. 57, no. 4, pp. 337-342, 2015, doi: 10.3139/120.110714. 